\title{
Sealant Effectiveness for Children Receiving a Combination of Preventive Methods in a Fluoridated Community: Two-Year Results
}

\author{
Robert A. Bagramian, Richard C. Graves, and Sujan Srivastava \\ Department of Community Dentistry and Program in Dental Public Health, School of \\ Dentistry, The University of Michigan, Ann Arbor, Michigan 48109, USA
}

$A$ series of preventive methods in combination have been used to reduce dental caries in children including dental health education, prophylaxes, pit and fissure sealants, topical application of fluoride and restorative care. Prophylaxes, sealant, and fluoride procedures are repeated every six months. Two-year results show reductions of occlusal caries increments of $74.3 \%$ for first graders and $77.1 \%$ for sixth graders. Sealant loss, as defined in this study, varied from $33 \%$ to $90 \%$ with the highest loss occurring in the newly erupted permanent molars during the first six months of the project. These high sealant loss rates are thought to be related to the age of the population which was designed to include children at the ages of peak eruption of permanent molar teeth (ages six and twelve). These teeth were often only minimally erupted and maintaining the dry field re. quired for sealant retention was extremely difficult. However, in spite of these high rates of sealant loss, caries reduction on occlusal surfaces was highly significant in comparison to that of children who did not receive sealants.

\section{J Dent Res 56(12): 1511-1519, December 1977.}

Several studies on sealant effectiveness in the prevention of caries have been conducted in recent years reporting wide variations in results. Equally varying results have been observed when the same material was used as a sealant as when different materials were used..$^{1-5}$ Generally, a high degree of caries reduction and sealant retention has been reported for those studies in which a Bis-GMA sealant (Nuva-seal) was used. It has been shown that the protection lasts for about two years, although the ultimate length

Received for publication April 26, 1936.

Accepted for publication February 15, 1977.

This paper is based on a presentation made at the Annual Meeting of the International Association for Dental Research (American Section), March 25-28, 1976, Miami Beach, Florida.

This research is supporsed by Contracl Number NiH-NIDR 72-240I.

*The L. D. Caulk Co., Division of Dentsply International Inc. of time for which it lasts is yet to be determined.$^{6}$ Since sealants are effective on only pit and fissure surfaces, it has been suggested that they be used in conjunction with other preventive methods which primarily affect smooth surfaces. Many of the studies on sealants were designed to include only a few selected and fully erupted teeth in the mouth for which contralateral or homologous pairs were found. ${ }^{3-5,7-8} \mathrm{Un}$ der these circumstances it is possible to carefully isolate individual teeth for sealant application. The purpose of the present study was to reduce caries as much as possible and therefore the occlusal surfaces of all sound teeth including newly erupted and erupting teeth in which the occlusal surface had penetrated the gingival tissue were included. This approach was used in order to more closely parallel the situation which would normally exist in a child population under care in the private practice of a clinical dentist or school clinic.

The study used a sealant (Nuvaseal)* which required ultraviolet light for polymerization. The purpose of this paper is to present findings at the end of two years on (1) the effectiveness of the sealant in caries prevention, and (2) the retention pattern of the sealant.

\section{Methods}

Through a contract with the National Institute of Dental Research, a 3-year project was undertaken to reduce the prevalence of dental caries in a population of school children residing in areas of communal water fluoridation. ${ }^{9.10}$ To test the effectiveness of combined preventive procedures, more than 600 first and sixth grade children were randomly selected. Most of these children belong to families of low to low-middle socioeconomic levels living in Ypsilanti, a city of approximately 30,000 people in a highly populated urban area of Southeastern Michigan. They have little or no access 
TABLE 1 .

TWO-YEAR DMFT INCREMENT IN FIRST GRADE CHILDREN YPSILANII, MICHIGAN, 1973-1975

\begin{tabular}{|c|c|c|c|c|c|}
\hline \multirow[b]{2}{*}{ Group } & \multirow[b]{2}{*}{$\mathrm{N}$} & \multicolumn{2}{|c|}{ Baseline Exam } & \multicolumn{2}{|c|}{$\begin{array}{c}\text { Increment From } \\
\text { Baseline To Second Year }\end{array}$} \\
\hline & & Mean & S.E. & Mean & S.E. \\
\hline Treatment & 258 & 0.2558 & 0.0458 & 0.3333 & 0.0499 \\
\hline Comparison & 276 & 0.2681 & 0.0459 & 0.9420 & 0.0754 \\
\hline "t" Statistic & & \multicolumn{2}{|c|}{0.1898} & \multicolumn{2}{|c|}{$6.7185^{*}$} \\
\hline
\end{tabular}

* Significant at $P<0.01$

TABLE 2

TWO-YFAR DMFS INCREMENT IN FIRST GRADE CHILDREN, YPSILANTI, MICHIGAN. 1973-1975

\begin{tabular}{lccccc}
\hline & & & & & \multicolumn{2}{c}{$\begin{array}{c}\text { Increment From } \\
\text { Baseline To Second Year }\end{array}$} \\
\cline { 3 - 6 } Group & $N$ & Mean & S.E. & Mean & S.E. \\
\hline Treatment & 258 & 0.3411 & 0.0661 & 0.4922 & 0.0811 \\
Comparison & 276 & 0.3406 & 0.0629 & 1.3768 & 0.1193 \\
"t" Statistic & & & 0.0055 & & $6.1345^{*}$ \\
\hline
\end{tabular}

* Significant at $P<0.01$

to dental care.

These children, henceforth to be considered as belonging to the treatment group, were exposed to the following procedures: (1) An oral hygiene program in classrooms, including supervised tooth brushing and flossing, aided by disclosing tablets for 32 weeks in the year, and dietary counseling. (2) Dental examination followed by prophylaxis every six months. (3) Application of Bis-GMA pit and fissure sealant (Nuvaseal, Buonocore Method) to the occlusal surface of eligible posterior teeth which lost sealant either completely or partially. This procedure was also done every six months. (4) Topical application of acidulated phosphate fluoride containing $1.23 \%$ fluoride in a tray for four minutes every six months. (5) Restoration of all affected teeth semi-annually.

A comparison group of an equal number of children was also randomly selected from the first and sixth grades of the same schools as the treated children. These children necessarily consume fluoridated water and, in addition, are also provided dental health education in the classroom like their classmates in the treatment group, which is coordinated by a dental hygienist with a background in education. The other procedures are conducted at 18 schools by dentists and auxiliaries utilizing two mobile dental vans. First and sixth grade children were selected since children at these ages have larger num- bers of newly-erupted and erupting permanent teeth which are highly susceptible to caries first molars in the first graders and bicuspids and second molars in the sixth graders.

All children are examined annually by two trained and calibrated dental epidemiologists employing highly standardized examination methods. Criteria used to assess dental caries are those developed at the 1968 ADA Conference on the Clinical Testing of Cariostatic Agents. Blindness to the extent possible is maintained during the study. During the examination process, previous examination records are not available to the two examiners. Subjects from both the treatment and comparison groups are intermixed. Posterior bite-wing radiographs are taken, interpreted and charted on a separate form by a dentist who is not an examiner, without benefit of the results of the clinical examination. Radiographic findings are then added to the clinical data. However, children in the treatment group are examined for decay and sealant retention at six-month intervals in addition to the annual examinations provided for all participants. During the initial examinations, the occlusal surfaces of all posterior teeth are indicated for sealant application if these surfaces are free of obvious decay or restoration or the interproximal surface is caries-free and the teeth have erupted at least to the extent that the full occlusal surface has 
penetrated the gingiva. The application of sealant was performed according to the method of Buonocore ${ }^{11.12}$ by two staff dentists who were trained in the procedures employed.

The occlusal surfaces were first cleaned with a nonfluoride prophylactic paste and cleansed thoroughly; then one quadrant at a time was selected for treatment. The teeth were isolated with cotton rolls, air dried, then etched for one minute per tooth using $50 \%$ phosphoric acid solution. The teeth were then flushed free of the etchant, redried, and the sealant applied and allowed to polymerize under a 30-second exposure to ultraviolet light. The tooth surfaces were then checked with an explorer for thoroughness of coverage and completeness of polymerization. If any areas of the fissured surfaces were not adequately covered and free of any catches, sealant was reapplied. To reduce the possibility of interference with retention, the topical fluorides were always applied after the application of sealants.

An evaluation of the condition of the sealant and the degree of retention is made at each sixmonth dental examination. With the aid of mirror and explorer, the occlusal surfaces of teeth are examined visually and tactilely for the presence of sealant. If none can be detected, the sealant is considered completely lost; if all pits and fissures are covered, the sealant is con- sidered completely retained; all other possibilities ranging from a small amount of sealant detectable to nearly all present are classified as partially retained. If an explorer catches in any portion of a pit or fissure, that tooth is considered to have lost sealant. In addition, posterior teeth which have erupted since the previous examination also receive sealant application.

\section{Results}

Tables 1 through 10 provide information on the children who remained in the study after two years. The randomization process apparently divided the study population into two comparable groups because baseline dental examinations revealed that the mean DMFT and DMFS scores were not significantly different for either the first or sixth grade children as demonstrated in Tables 1 through 4 . However, at the end of two years, mean differences in these caries increments were all statistically significantly different $(P<0.01)$. As observed in Tables 1 through 4 , the increments are such that the percent of reduction in DMFT and DMFS is about $65 \%$ for the treated first graders and $70 \%$ in DMFT and $54 \%$ in DMFS for treated sixth graders.

An analysis of the caries increment data by surface type (Tables 5 and 6 ) in the first and sixth grade children reveals hittle difference be-

TABLE 3

TWO-YEAR DMFT INCREMENT IN SIXTH GRADE CHILDREN YPSILANTI MICHIGAN, 1973-1975

\begin{tabular}{|c|c|c|c|c|c|}
\hline \multirow[b]{2}{*}{ Group } & \multirow[b]{2}{*}{$N$} & \multicolumn{2}{|c|}{ Baseline Exam } & \multicolumn{2}{|c|}{$\begin{array}{l}\text { Increment From } \\
\text { Baseline To Second Year }\end{array}$} \\
\hline & & Mean & S.E. & Mean & S.E. \\
\hline Treatment & 233 & 3.2489 & 0.1585 & 0.6094 & 0.0942 \\
\hline Comparison & 226 & 3.2522 & 0.1657 & 2.0265 & 0.1675 \\
\hline "t" Statistic & & \multicolumn{2}{|c|}{0.0144} & \multicolumn{2}{|c|}{$7.3692^{*}$} \\
\hline
\end{tabular}

* Significant at $P<0.01$

TABLE 4.

TWO-YEAR DMFS INCREMENT IN SIXTH GRADE CHILDREN YPSILANTI, MICHIGAN, 1973-1975

\begin{tabular}{|c|c|c|c|c|c|}
\hline \multirow[b]{2}{*}{ Group } & \multirow[b]{2}{*}{$\mathrm{N}$} & \multicolumn{2}{|c|}{ Baseline Exam } & \multicolumn{2}{|c|}{$\begin{array}{c}\text { Increment From } \\
\text { Baseline To Second Year }\end{array}$} \\
\hline & & Mean & S.E. & Mean & S.E. \\
\hline Treatment & 233 & 5.4592 & 0.3248 & 1.4249 & 0.1889 \\
\hline Comparison & 226 & 5.5177 & 0.3304 & 3.1106 & 0.3029 \\
\hline "t" Statistic & & \multicolumn{2}{|c|}{0.1263} & \multicolumn{2}{|c|}{$4.7232^{*}$} \\
\hline
\end{tabular}

* Significant at $P<0.01$ 
TABLE 5.

TWo-Year DMFS INCREMENT by SURFACE TyPe In FIRST GRADE ChILdREN. YPSILANTI, MICHIGAN, 1973-1975

\begin{tabular}{|c|c|c|c|c|c|c|c|}
\hline \multirow[b]{2}{*}{ Group } & \multicolumn{3}{|c|}{$\begin{array}{l}\text { Buccolingual } \\
\text { Increment }\end{array}$} & \multicolumn{2}{|c|}{$\begin{array}{l}\text { Mesiodistal } \\
\text { Increment }\end{array}$} & \multicolumn{2}{|c|}{$\begin{array}{l}\text { Occlusal } \\
\text { Increment }\end{array}$} \\
\hline & $N$ & Mean & S.E. & Mean & S.E. & Mean & S.E. \\
\hline Treatment & 258 & 0.1938 & 0.0381 & 0.0736 & 0.0305 & 0.2248 & 0.0409 \\
\hline Comparison & 276 & 0.4239 & 0.0578 & 0.0797 & 0.0212 & 0.8732 & 0.0743 \\
\hline "t"Statistic & \multicolumn{3}{|c|}{$3.325 l^{*}$} & \multicolumn{2}{|c|}{0.1694} & \multicolumn{2}{|c|}{$7.6462^{*}$} \\
\hline
\end{tabular}

*Significant at $P^{\circ}<0.01$

TABLE 6.

TWO-Year DMFS INCREMENT By SURFACE TYPE IN SIXTH GRade CHILDREN, YPSILANTI, MICHIGAN, 1973-1975

\begin{tabular}{|c|c|c|c|c|c|c|c|}
\hline \multirow[b]{2}{*}{$\overline{\text { Group }}$} & \multirow[b]{2}{*}{$N$} & \multicolumn{2}{|c|}{$\begin{array}{l}\text { Buccolingual } \\
\text { Increment }\end{array}$} & \multicolumn{2}{|c|}{$\begin{array}{l}\text { Mesiodistal } \\
\text { Increment }\end{array}$} & \multicolumn{2}{|c|}{$\begin{array}{c}\text { Occlusal } \\
\text { Increment }\end{array}$} \\
\hline & & Mean & S.E. & Mean & S.E. & Mean & S.E. \\
\hline Treatment & 233 & 0.4077 & 0.0725 & 0.6438 & 0.1124 & 0.3734 & 0.0753 \\
\hline Comparison & 226 & 0.5354 & 0.1127 & 0.9469 & 0.1551 & 1.6283 & 0.1306 \\
\hline "t"Statistic & \multicolumn{3}{|c|}{0.9523} & \multicolumn{2}{|c|}{1.5828} & \multicolumn{2}{|c|}{$8.3161^{*}$} \\
\hline
\end{tabular}

*Significant at $P<0.01$

tween the treatment and comparison groups regarding buccolingual and mesiodistal surfaces of the permanent teeth. Although the buccolingual increment for the first graders is statistically significantly greater in the comparison group, the absolute values are low and thus of questionable clinical significance. However, the occlusal surface increment is approximately fourfold in the comparison group over that seen in the treatment group for both grades, a highly significant difference statistically $(P<0.01)$. These differences represent a reduction in occlusal surface increment of $74.3 \%$ for first graders and $77.1 \%$ for sixth graders.

In contrast to a high degree of caries reductions on occlusal surfaces for the treated children, evaluations of sealant retention at the end of two years indicate a relatively low rate of sealant retention (Table 7 ). Complete retention for two years was particularly low for the first permanent molars of first graders and second molars of sixth graders. However, as Table 7 indicates, the percent of these surfaces which became decayed, missing or filled during the two years was only about 8 to $9 \%$. For the purposes of this report, three possible outcomes of sealant evaluations are indicated in Table 7 . At the end of two years, as may be noted for the 659 first permanent molars sealed at baseline in the first graders, (1) 100 teeth or $15.2 \%$ had sealant completely intact, (2) 51 teeth or $7.7 \%$ be- came decayed, missed or filled on the occlusal surface, and (3) 508 teeth or $77.1 \%$ required resealing at least once. The degree of complete retention for the second permanent molar was even lower at $9.7 \%$ whereas the percent of carious history was $9.0 \%$. The bicuspids exhibited a retention rate of $51.8 \%$ and decay rate of $2.5 \%$. By contrast, the primary molars had sealant intact to the extent of $66.5 \%$ after two years and yet $14.2 \%$ of these teeth had occlusal surfaces that were decayed, missing, or filled. Thus, the results indicate greater sealant retention for primary molars of younger children followed by bicuspids and first permanent molars in older children, which is consistent with our earlier findings and those of other researchers. ${ }^{2.3 .7}$

Those sealed teeth which were found to have developed caries, or were restored, or were found missing over the two-year period under investigation were further subclassified in Table 8. Since sealant is applied on occlusal surfaces of teeth, their efficacy in caries prevention is measured by the number of decayed and filled occlusal surfaces only. Caries confined to the occlusal surface alone may be attributable to failure of the sealant. Hence, all mesiodistal and buccolingual restorations not involving the occlusal surface have been excluded in Tables 7 and 8 . Conversely, all proximo-occlusal restorations were included under decayed, missing, 
and filled teeth in Table 7 , and these in turn have inflated the sealant failure figures because the restoration of these interproximal surfaces necessarily involves the occlusal surface whether decayed or not. The information presented in Table 8 is an attempt to resolve this problem.

The number of occlusal restorations observed at the time of semi-annual examinations were divided into two categories as indicated by the location of caries that had resulted in a restoration involving the occlusal surface: (1) either a purely occlusal restoration, or (2) a proximoocclusal restoration. This separation measures the extent to which figures on restorations due to occlusal caries are inflated. It is clear from Table 8 that of the total number classified as decayed, missing, and filled occlusal surfaces, $74 \%$ of the primary molars, $54.8 \%$ and $51.7 \%$ of the bicuspids and first molars respectively in sixth graders had proximo-occlusal restorations done. These teeth, were it not for interproximal caries, would likely have not required occlusal involvement. Hence, the number of cases of sealant failure for these tooth types is far less than what it appears to be. However, the first permanent molars in the younger children and the second permanent molars in the older children have made little contribution to this difference since for these teeth almost all the decay occurred on the occlusal surface.

Table 9 illustrates the length of time sealant was retained in different tooth types for first and sixth grade children. Table 7 indicates that the first permanent molars in younger children and second permanent molars in older children have the smallest percentage of sealant intact at the end of two years. Table 9 reveals that over a two-year period the majority of sealant loss occurs by the end of the first six months. Sealant loss was greater than $50 \%$ in both the first permanent molars in first graders and the second permanent molars in sixth graders during the first six months.

The average number of sealant reapplications by tooth type is presented in Table 10. As would be expected the greatest number of reapplications were necessary for those tooth types having the lowest retention. However, the mean number of reapplications required varies only from a low of 1.4 times for bicuspids to a high of 2.1 times for second permanent molars. This difference was not so highly significant $(.01<$ $P<0.05$ ). Thus, even though a high percent. age of the first molars in first graders and second molars in sixth graders needed reapplication after six months, retention tended to stabilize beyond that point so that reapplications required were relatively comparable for the various tooth types. Further, no significant difference was found in the number of sealant reapplications done on teeth with regard to their respective positions in the mouth.

\section{Discussion}

Although it is difficult to directly assess the benefit of sealant applications in this popula. tion because of the combination of preventive methods used, several observations can be made. The level of caries incidence is relatively low for the entire population because of an optimally fluoridated water supply. The caries preventiveness that occurs from both water fluoridation and topical applications of fluorides affects smooth surfaces to a large extent

TABLE 7.

SEALANT STATUS By TOOTH TYPE AT THE END OF TWO YEARS

IN FIRST AND SIXTH GRADE CHILDREN

YPSILANTI, MICHIGAN, 1973-1975

\begin{tabular}{|c|c|c|c|c|c|c|c|}
\hline \multirow[b]{2}{*}{ Tooth Type } & \multirow[b]{2}{*}{$\begin{array}{l}\text { Number Sealed } \\
\text { At Baseline }\end{array}$} & \multicolumn{2}{|c|}{ Sealant Intact } & \multicolumn{2}{|c|}{$\begin{array}{l}\text { Decayed, Missing } \\
\text { and Filled } \\
\text { Occlusal Surfaces }\end{array}$} & \multicolumn{2}{|c|}{ Resealed } \\
\hline & & No. & $\%$ & No. & $\%$ & No. & $\%$ \\
\hline Primary Molars & & & & & & & \\
\hline $\begin{array}{l}\text { First Graders . . . . . } \\
\text { First Perm Molars }\end{array}$ & 1214 & 807 & 66.5 & 173 & 14.2 & 234 & 19.3 \\
\hline $\begin{array}{l}\text { First Graders . . . . . } \\
\text { Bicuspids }\end{array}$ & 659 & 100 & 15.2 & 51 & 7.7 & 508 & 77.1 \\
\hline $\begin{array}{l}\text { Sixth Graders . . . } \\
\text { First Perm. Molars }\end{array}$ & 1246 & 646 & 51.8 & 31 & 2.5 & 569 & 45.7 \\
\hline $\begin{array}{l}\text { Sixth Graders ..... } \\
\text { Second Perm. Molars }\end{array}$ & 361 & 125 & 34.6 & 29 & 8.1 & 207 & 57.3 \\
\hline Sixth Graders .... & 300 & 29 & 9.7 & 27 & 9.0 & 244 & 81.3 \\
\hline
\end{tabular}


TABLE 8.

Pattern of Dental Caries in Relation to SEalant AT THE END Of Two Years in First and Sixth Grade ChILdREN YPSILANTI MICHIGAN. 1973-1975

\begin{tabular}{|c|c|c|c|c|c|c|c|c|c|}
\hline \multirow[b]{2}{*}{ Tooth Type } & \multirow{2}{*}{$\begin{array}{c}\begin{array}{c}\text { Decayed, Missing } \\
\text { and Filled Occlu- } \\
\text { sal Sur faces }\end{array} \\
\text { No. }\end{array}$} & \multicolumn{2}{|c|}{$\begin{array}{l}\text { Decayed Occlusal } \\
\text { Surfaces }\end{array}$} & \multicolumn{2}{|c|}{$\begin{array}{l}\text { Missing Due To } \\
\text { Caries }\end{array}$} & \multicolumn{2}{|c|}{$\begin{array}{l}\text { Filled Due To } \\
\text { Occlusal } \\
\text { Decay }\end{array}$} & \multicolumn{2}{|c|}{$\begin{array}{c}\text { Filled Due To } \\
\text { Interproximal } \\
\text { Decay }\end{array}$} \\
\hline & & No. & $\sigma_{0}$ & No. & $\%$ & No. & $v_{0}$ & No. & $\%$ \\
\hline Primary Molars & & & & & & & & & \\
\hline $\begin{array}{l}\text { First Graders ..... } \\
\text { First Molars }\end{array}$ & 173 & 2 & 1.1 & 5 & 2.9 & 38 & 22.0 & 128 & 74.0 \\
\hline $\begin{array}{l}\text { First Graders . . . . . } \\
\text { Bicuspids }\end{array}$ & 51 & 23 & 45.1 & 0 & 0.0 & 25 & 49.0 & 3 & 5.9 \\
\hline $\begin{array}{l}\text { Sixth Graders } \ldots . . \\
\text { First Molars }\end{array}$ & 31 & 1 & 3.3 & 0 & 0.0 & 13 & 41.9 & 17 & 54.8 \\
\hline $\begin{array}{l}\text { Sixth Graders .... } \\
\text { Second Molars }\end{array}$ & 29 & 1 & 3.5 & 0 & 0.0 & 13 & 44.8 & 15 & 51.7 \\
\hline Sixth Graders . . . . & 27 & 7 & 25.9 & 0 & 0.0 & 20 & 74.1 & 0 & 0.0 \\
\hline
\end{tabular}

whereas sealants exhibit their effect only on pit and fissure surfaces. Even in this population with a low caries increment because of a fluoridated water supply, significant differences have been demonstrated between treatment and comparison children. The major effect has been demonstrated to have occurred on the oc: clusal surfaces where the pit and fissure sealant has been applied. As observed in Table 5, there is virtually no mesiodistal increment in either treated or comparison children which is expected because the children advance in age from six years to eight years, a period during which caries susceptibility in interproximal surfaces of permanent teeth is particularly low in fluoridated communities and largely limited to first molars. The buccolingual increments are also relatively small during the two years and most of the carious lesions found occur in buccal grooves of lower molars and lingual grooves of upper molars. In comparison, the mean occlusal increment of 0.22 indicates that the treated group required 22 teeth restored per 100 children, whereas the untreated group required 87 teeth restored per 100 children.

The comparative caries reduction achieved for the older children is similar to the younger ones (Table 6) in that buccolingual and mesiodistal surface increments were not significantly different in the treated and untreated children. However, because these children are now ap. proximately 13 years old and have more teeth which have been at risk for a longer time, the increments are larger in the older children. The comparative effectiveness of the sealants is evident from the indication that 163 occlusal sur- faces per 100 children were involved in the comparison group in contrast to only 37 surfaces per 100 treated children.

The two-year complete sealant retention figures reported in this study (Table 7) are much less than those reported in other studies which tested the same material. Buonocore ${ }^{12}$ reported an $87 \%$ level of complete retention; Horowitz et $\mathrm{al}^{8}$ reported a $37 \%$ level for second molars and $48 \%$ retention for first permanent molars; Rock $^{14}$ reported an $80 \%$ level; Going and coworkers $^{7}$ a $69 \%$ level with a $78 \%$ level for first molars and $53 \%$ for second molars. However, only $39 \%$ overall retention was reported by Burt et $\mathrm{al}^{2}$ at the end of six months. Extremely low retention rates at the end of one year were also reported by Stephen et al. ${ }^{15}$

There are several possible reasons why these differences should be so marked. One is that the criteria for tooth selection used in this study were very different from those used in other studies. The higher percentage of retention reported by Buonocore ${ }^{12}$ might be explained by his careful selection of teeth that had well-defined pits and fissures, or deep fossae, or both. In all these studies except that undertaken by Stephen et $a^{15}$ paired sound permanent teeth were selected and a half-mouth technique was used. That is, one side of the mouth of each patient was randomly selected for treatment, and the other served as the untreated control. In the present study, all sound eligible teeth in the mouth were sealed irrespective of whether a tooth had a matching sound pair or not. A good number of teeth on the treated side were 
unpaired at the time of the study's initiation because their contralateral homologue had already decayed. These unpaired treated teeth were likely more susceptible to dental caries and hence loss of sealant than paired sound teeth. The fact that sealant retention for the unpaired permanent teeth is generally not as good as in paired permanent teeth has been demonstrated by Going et al. ${ }^{7}$ and Horowitz et al. ${ }^{8}$

Considerable sealant loss is likely related to the design of the study in that, in an effort to provide preventive measures to the permanent teeth as early as possible after eruption, all study children were either six years old and thus had erupting first molars or eleven years old and had erupting second molars. The inability to carefully isolate these molars and maintain a dry field would contribute to the high rate of sealant loss revealed in Table 7 . Access was also a factor in that is was often difficult to maintain the tip of the quartz rod of the UV light in the proper position for the necessary time to provide optimum polymerization of the sealant in these partially erupted, distally positioned molars. The distal fossa of the occlusal surface of upper molars posed the greatest problem with a prominent transverse ridge often creating an additional barrier to adequate access of the UV light rays. The examiners noted that sealant loss was observed more frequently in the more distal aspects of the occlusal surfaces. This explanation is strengthened by the data provided in Tables 9 and 10. Table 9 indicated a greater than $50 \%$ loss of sealant within six months for first molars in first grade children and second molars in sixth graders, when these teeth would be minimally erupted. However, the numbers of reapplications required (Table 10 ) suggests that sealant loss rates stabilize at lower levels beyond the first six months.

Another factor that could exert bias in the direction of high reported sealant loss rates is that the primary thrust of the study was to reduce caries to the greatest extent possible. Because all teeth were being reexamined every six months and sealant reapplied, if any doubt existed regarding the completeness of sealant coverage, the tendency was to "err in the direction of safety" and to score these teeth for sealant reapplication. The sealant was utilized in its clear form rather than with the incorporation of a red dye as was done by Going et al, ${ }^{7}$ which could aid visual detection and reduce errors. Because reported retention rates are based on the ability to detect the material on a tooth surface and do not necessarily reflect sealant retained in deeper portions of pits and fissures not easily accessible to examination with an explorer, actual protection from caries may greatly exceed the degree of protection implied by low rates of retention. Thus, a relatively low incidence of occlusal decay as observed in Table 7 may occur even though sealant loss appears to be relatively high.

In addition, the percent of retention reported in Table 7 and the length of sealant retention given in Table 9 considers only the data for complete retention and does not include any degree of partial retention of sealant. Thus, if, in the examiner's judgment any portion of a fissured surface of a tooth could benefit from reapplication of sealant, that tooth is considered not to have a completely retained sealant.

In an attempt to reduce bias, the examining dentists who scored sealant status did not apply the material or have any previous knowledge as to whether certain tooth sites had received sealant, as, for example, when a molar was unerupted at the previous visit. In some studies, ${ }^{12.14}$

TABLE 9.

Sealant Retention over a Two-Year Period by Length of Time in

FIRST AND SIXTH GRADF CHILDREN.

YPSILANTI. MICHIGAN, 1973-1975

\begin{tabular}{|c|c|c|c|c|c|c|c|c|c|c|c|}
\hline \multirow[b]{2}{*}{ Tooth Type } & \multirow[b]{2}{*}{ No. } & \multicolumn{2}{|c|}{$<6$ Mos. } & \multicolumn{2}{|c|}{ 6-12 Mos. } & \multicolumn{2}{|c|}{ 12-18 Mos. } & \multicolumn{2}{|c|}{ 18-24 Mos. } & \multicolumn{2}{|c|}{$24+$ Mos. } \\
\hline & & No. & $0 ; 0$ & No. & $\%$ & No. & $\%$ & No. & $\%$ & No. & $\theta$ \\
\hline \multicolumn{12}{|l|}{ Primary Molars } \\
\hline $\begin{array}{l}\text { First Graders ............. } \\
\text { First Perm. Molars }\end{array}$ & 1041 & 137 & 13.2 & 35 & 3.4 & 43 & 4.1 & 19 & 1.8 & 807 & 77.5 \\
\hline $\begin{array}{l}\text { First Graders } \ldots \ldots \ldots \ldots \ldots \ldots \\
\text { Bicuspids }\end{array}$ & 608 & 339 & 55.8 & 83 & 13.6 & 49 & 8.1 & 37 & 6.1 & 100 & 16.4 \\
\hline Sixth Graders. . . . . . . . . . & 1215 & 228 & 18.8 & 138 & 11.3 & 135 & 11.1 & 68 & 5.6 & 646 & 53.2 \\
\hline First Perm. Molars . . . . . . . . . & 332 & 80 & 24.1 & 54 & 16.3 & 48 & 14.5 & 25 & 7.5 & 125 & 37.6 \\
\hline Second Perm. Molars. . . . . . . . & 273 & 144 & 52.8 & 64 & 23.4 & 29 & 10.6 & 7 & 2.6 & 29 & 10.6 \\
\hline
\end{tabular}

Sixth Graders 


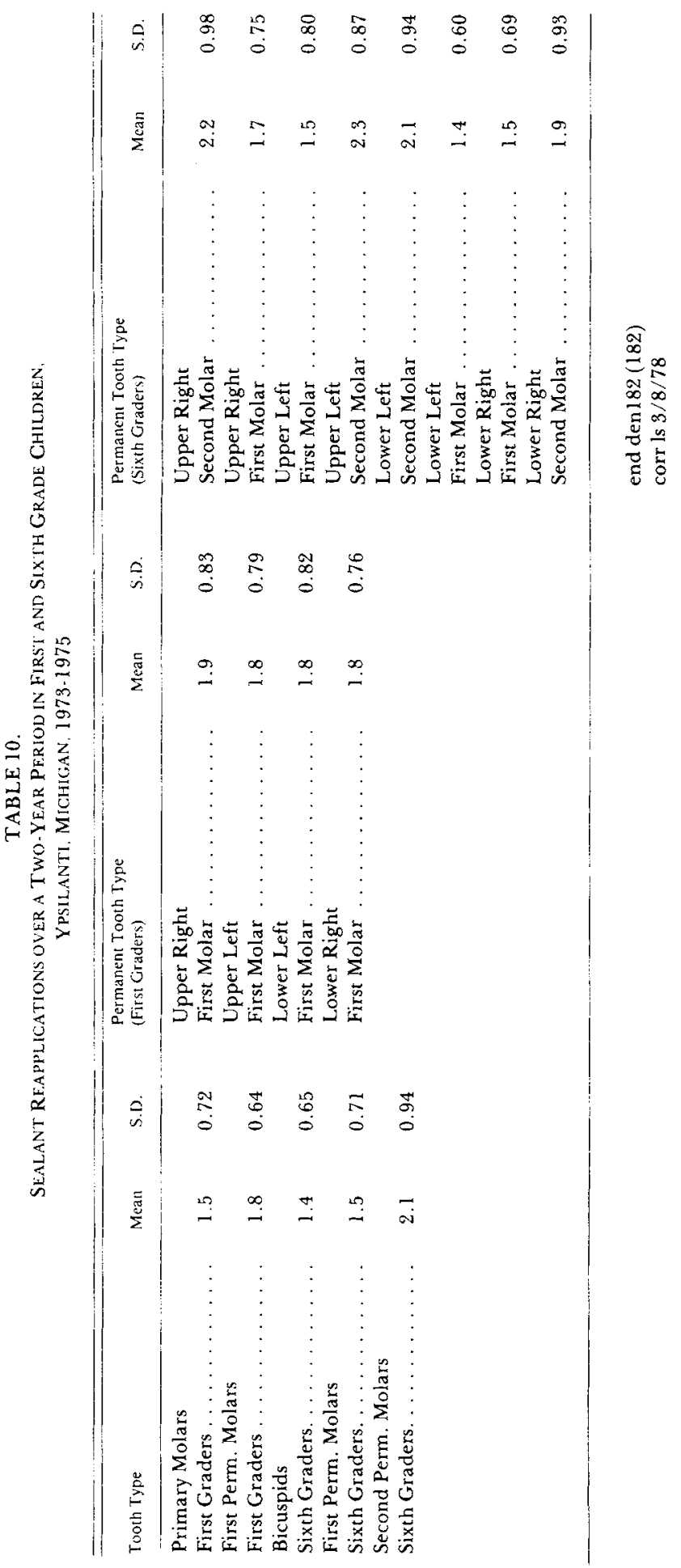


it appears that the same person served both as clinician and examiner which could bias scores even though certainly unintended. In the Kalispell study of Horowitz et $\mathrm{al}^{8}{ }^{8}$ it was pointed out that completely blind examinations could not be conducted. It is also recognized that teeth with optimal levels of fluoride may not "etch" with acid conditioners as readily as nonfluoridated teeth. ${ }^{16}$ Teeth from areas of high fluoridation were shown to be highly resistant to etching by citric acid and phosphoric acid. This problem could be another cause for low retention rates in this study and, hence, a justification for a prolonged etching time in fluoridated regions as suggested by Sharp and Grenoble. ${ }^{17}$

Still another factor, as cited by Stephen et $a_{1},^{15}$ is variation between individual NuvaLite units resulting in variations in ultraviolet emission. It is difficult to accurately apply the light source within the mouth. Variations in radiation levels and techniques applied provide another reason for differences in retention levels.

\section{Conclusions}

Even in communities that are optimally fluoridated and conduct a dental health education program, dental caries may be significant ly reduced further in children when additional preventive methods of topical fluoride and seal. ant applications and necessary restorative care are provided. In this study after two years, treated children who were initially six years old had a reduced DMFS increment of $64.3 \%$ and treated children who entered the project as eleven year olds experienced a DMFS increment reduction of $54.2 \%$ in contrast to their comparison groups. Percentage reductions in occlusal surface increments of $74.3 \%$ for younger children and $77.1 \%$ for the older children are even more impressive and reflect the impact of sealants. Retention of sealant was highest in the primary molars followed by bicuspids and first molars in younger children and second molars in the older group and appear to be related to their posterior position in the mouth and recency of eruption and the method of assessing loss. The greatest sealant loss and need for reappli. cation occurred within six months after initial application. However, even though sealant loss was relatively high, demonstrated by visual and tactile means, caries prevention continued at a high level.

\section{References}

I. Crowe, R. A.: An In Vitro Study of A Fissure
Sealant, $J$ LA Dent $A$ 29:1619, 1971.

2. Burt, B. A.; Berman, D. A.; Gelbier, S.; and Silverstone, L. M.: Retention of a Fissure Sealant Six Months After Application, Brit Dent $J$ 138:98-100, 1975.

3. ROCK, W. P.: Fissure Sealants: Results Obtained With Two Different Bis-GMA Type Sealants, Oral Health 63:9-12, 1973.

4. RipA, L. W., and Cole, W. M.: Occlusal Sealing and Caries Prevention: Results 12 Months After a Single Application of Adhesive Resin, $J$ Dent Res 49:171-173, 1970.

5. Rock, W. P.: Fissure Sealants: Results Obtained With Two Different Sealants After One Year, Brit DentJ 133:146-151, 1972.

6. Boudreal, G. E., and Jfrge, C. E.: The Efficacy of Sealant Treatment in the Prevention of Pit and Fissure Dental Caries, a Review and Interpretation of the Literature, $J A D A$ $72: 383-386,1976$.

7. Going, R. E.; Haugh, L. D.; Granger, D. A.; and Contr, A. J.: Two Year Clinical Evaluation of a Pit and Fissure Sealant Part 1 : Retention and Loss of Substance, JADA 92:388-397, 1976.

8. Horowitz, H. S.; HeIFETZ, S. B.; and MCCune, R. J.: The Effectiveness of an Adhesive Sealant in Preventing Occlusal Caries: Findings After Two Years in Kalispell, Montana, JADA 89:885-890, 1974.

9. Bagramian, R. A.; Grayes, R. C.; and Bhat, M.: A Combined Approach to Preventing Dental Caries in School Children: Caries Reduction After One Year, JADA 93:1014-1019, 1976.

10. Graves, R. C.; Bagramian, R. A.; and Bhat, M.: Pattern of Sealant Retention in Primary and Permanent Teeth -.. One Year's Findings, $J$ Dent Res 54: Abstract No. 183, 1975.

11. Buonocore, M. G.: Adhesive Sealing of Pits and Fissures for Caries Prevention, With the Use of Ultraviolet Light, $J A D A$ 80:324-328, 1970.

12. Buonocore, M. G.: Caries Prevention in Pits and Fissures Sealed With an Adhesive Resin Polymerized by Ultraviolet Light: A Two-Year Study of a Single Adhesive Application, JADA 82:1090-1093, 1971.

13. Buonocore, M. G.: Adhesive Sealing of Pits and Fissures for Caries Prevention, With the Use of Ultraviolet Light, $J A D A$ 80:324-328, 1970

14. RoCk, W. P.: Fissure Sealants: Further Results of Clinical Trials, Brit Dent J 136:317-321, 1974.

15. Stephen, K. W.; SuthlRland, D. A.; and Trainer, J.: Fissure Sealing by Practitioners First Year Retention Data in Scottish 6-Year-Old Children, Brit Dent J 140:45-51, 1976.

16. LEE, H.; STOFFEY, D.; ORLOWKSKI, J.; SWARTZ, M. L.; OCumpaugh, D.; and Neville, K.: Sealing of Developmental $p_{i t}$ and Fissures: III. Effects of Fluoride on Adhesion of Rigid and Flexible Sealers, J Dent Res 51:191-201, 1972.

17. Sharp, E. C.; and Grenobly, D. E.: Dental Resin Penetration Into Acid Etched Subsurface Enamel, IS Calif Dent Assoc 39:741-755, 1971. 